\title{
Attitude and skill levels of graduate health professionals in performing cardiopulmonary resuscitation
}

\author{
Endale Gebreegziabher \\ Gebremedhn' \\ Gebremedhn Berhe \\ Gebregergs ${ }^{2}$ \\ Bernard Bradley \\ Anderson ${ }^{3, \dagger}$ \\ Vidhya Nagaratnam'
}

'Department of Anaesthesia, School of Medicine, College of Medicine and Health Sciences, University of Gondar, Gondar, ${ }^{2}$ Department of Public Health, Bahir Dar College of Medicine and Health Sciences, Bahir Dar University, Bahir Dar, ${ }^{3}$ Department of Surgery, School of Medicine, College of Medicine and Health Sciences, University of Gondar, Gondar, Ethiopia

tDr Bernard Bradley Anderson passed away on January 2, 2014

Correspondence: Endale Gebreegziabher Gebremedhn

Department of Anaesthesia, School of Medicine, College of Medicine and Health Sciences, University of Gondar, PO Box 196, Gondar, Ethiopia

Tel +25। 910880 II7

Email endalege@yahoo.com
This article was published in the following Dove Press journal:

Advances in Medical Education and Practice

9 January 2017

Number of times this article has been viewed

Background: Cardiopulmonary resuscitation (CPR) is an emergency procedure used to treat victims following cardiopulmonary arrest. Graduate health professionals at the University of Gondar Teaching Hospital manage many trauma and critically ill patients. The chance of survival after cardiopulmonary arrest may be increased with sufficient attitude and skill levels. The study aimed to assess the attitude and skill levels of graduate health professionals in performing CPR Methods: A hospital-based cross-sectional study was conducted from May 1 to 30, 2013, at the University of Gondar Teaching Hospital. The mean attitude and skill scores were compared for sex, original residence, and department of the participants using Student's $t$-test and analysis of variance (Scheffe's test). $P$-values $<0.05$ were considered to be statistically significant.

Results: Of the 506 graduates, 461 were included in this study with a response rate of $91.1 \%$. The mean attitude scores of nurse, interns, health officer, midwifery, anesthesia, and psychiatric nursing graduates were 1.15 (standard deviation $[\mathrm{SD}]=1.67), 8.21(\mathrm{SD}=1.24), 7.2(\mathrm{SD}=1.49)$, $6.69(\mathrm{SD}=1.83), 8.19(\mathrm{SD}=1.77)$, and $7.29(\mathrm{SD}=2.01)$, respectively, and the mean skill scores were 2.34 ( $\mathrm{SD}=1.95), 3.77(\mathrm{SD}=1.58), 1.18(\mathrm{SD}=1.52), 2.16(\mathrm{SD}=1.93), 3.88(\mathrm{SD}=1.36)$, and $1.21(\mathrm{SD}=1.77)$, respectively.

Conclusion and recommendations: Attitude and skill level of graduate health professionals with regard to CPR were insufficient. Training on CPR for graduate health professionals needs to be given emphasis.

Keywords: cardiopulmonary resuscitation, attitude, skill, graduate health professionals

\section{Introduction}

Cardiopulmonary resuscitation (CPR) is an emergency procedure used to treat victims of cardiopulmonary arrest. It is an important life-saving technique, which can help maintain oxygenated blood circulation in the body. ${ }^{1} \mathrm{CPR}$ will be continued until the heart can be restarted. ${ }^{2}$

The quality of CPR mainly depends on the sufficiency of the attitude and skill of health professionals who deliver CPR..$^{3-6}$ Doubling the survival of patients from cardiopulmonary arrest requires improvement in resuscitation education. ${ }^{7-14}$ Studies conducted in Malaysia and Denmark showed that the attitude and skill levels of junior doctors were poor. Most of them were not confident in managing a resuscitation case and in leading a team. ${ }^{15-18}$

Studies conducted in Asia and Europe showed that the skill levels of qualified nurses were poor because of the lack of regular training and participation in real resuscitation sessions but were improved after training. ${ }^{19,20}$ A study carried out in Gorgan, Iran, reported similar findings that the performance of nursing and midwifery students in 
their last semester of study with regard to basic life support (BLS) and advanced cardiac life support (ACLS) programs were not adequate before training. ${ }^{21}$

Studies conducted in Iran and People's Republic of China showed that only a small number of medical students were confident in their ability to carry out CPR and felt that they can do it correctly. ${ }^{22,23}$ Likewise, in a study carried out in Norway, it was found that most of the nursing student teams did not perform defibrillation accurately during CPR. ${ }^{24}$

A research done in Pakistan found that the awareness $(66.6 \%)$ and skill (18\%) of medical students about BLS were low. ${ }^{25}$ The confidence level of newly graduated medical interns in performing CPR was substandard. ${ }^{26}$ The attitude of medical students toward CPR was good but that of nursing students was not as expected. ${ }^{27}$ The awareness of nursing students and interns about BLS was very poor. ${ }^{28}$ The skill levels of nurses and nursing students with regard to performing CPR were insufficient. ${ }^{29}$ The attitude of medicine, nursing, and pharmacy students toward CPR was good, but knowledge and skill required to perform CPR were insufficient. ${ }^{30}$

A study done in Norway showed that medical laboratory technologists, physiotherapists, and occupational health safety and midwifery professionals carried out CPR on a large number of actual patients and took a course on CPR more recently compared with nurses. ${ }^{31}$

Similarly, a study done in Nigeria observed that the knowledge and confidence level of anesthesia trainees about CPR was poor. ${ }^{32}$ Despite the fact that all graduate health professionals took CPR training in undergraduate course and were involved in the management of many trauma and critically ill patients at the University of Gondar Teaching Hospital, our previous study showed that the knowledge level of these graduates with regard to CPR was substandard.$^{33}$ The study aimed to assess the attitude and skill level of graduate health professionals in performing CPR.

\section{Methods}

\section{Study design and period}

A hospital-based cross-sectional study was conducted from May 1 to 30, 2013.

\section{Study subjects}

All graduate health science students (anesthesia, health officer, nurse, midwifery, and psychiatry nurse) and interns who were present at the University of Gondar Referral and Teaching Hospital during the study period were included in the study. Students who were sick during data collection and environmental/occupational health and safety, pharmacy, medical laboratory, optometry, and physiotherapy students who had no exposure to CPR activities were excluded.

\section{Study tools}

A structured questionnaire was developed that addressed sociodemographic variables, field of study of students, and attitude and skills of participants about BLS and ACLS based on the 2010 UK Resuscitation Council Guidelines. ${ }^{34}$ The questionnaire was validated and pilot tested in other hospitals, and changes were made before the study. Ten attitude and eight skill questions were included and each correct answer was given a score of one point. The attitude level was classified as sufficient for students who answered more than eight out of ten questions correctly (>80\%) and insufficient for those who answered eight or less out of ten questions correctly ( $<80 \%$ ) according to the 2005 American Heart Association (AHA) accreditation criteria. ${ }^{35}$

In addition, the skill level of the students was classified as sufficient for students who answered more than six out of eight questions correctly ( $>80 \%$ ) and insufficient for those who answered six or less out of eight questions correctly $(<80 \%)$ according to the 2005 AHA accreditation criteria.

\section{Operational definitions}

\section{Attitude}

The term refers to the affective domain that includes "learner's" values, beliefs, and role expectations that may influence the management of patients.

\section{Skills}

The term refers to the actual abilities to put specific knowledge into practice (performance or clinical competence).

\section{Graduate students}

Final year undergraduate (graduate) health science students and medical interns are referred to as graduate students.

\section{Ethical considerations}

Ethical clearance was obtained from the institutional ethical review board of the University of Gondar. Verbal informed consent was obtained from each study subject and confidentiality was ensured using an anonymous questionnaire.

\section{Data collection procedures}

We distributed the questionnaires to students of the respective departments after morning sessions and classes. An English version of the self-administered questionnaire was used to collect data from the students, as the medium of instruction at the University of Gondar is English. 


\section{Data processing and analysis}

Data were analyzed using SPSS windows version 20.0 software (IBM Corporation, Armonk, NY, USA). The mean scores of attitude and skill were compared for sex, original residence, and department of the students by using $t$-test and analysis of variance (ANOVA) with Scheffe's test. $P$-values $<0.05$ were considered to be statistically significant.

\section{Results}

\section{Sociodemographic characteristics of respondents}

Of the 506 final year undergraduate students belonging to different departments, we included only 461 in our study, with a response rate of $91.1 \%$; of the 45 excluded students, 21 were due to incomplete filling of questionnaires, 20 refused to participate in the study, and four because of sickness.

Males accounted for $66.4 \%$ of the respondents. The minimum, maximum, and mean ages of the students were 19,39 , and 23 years, respectively. The original residences of $244(52.9 \%)$ students were in the urban areas.

The majority of the students were interns (135 [29.3\%]), followed by nurses (123 [26.7\%]), health officers (80 [17.4\%]), midwifery (77 [16.7\%]), anesthesia (32 [6.9\%]), and psychiatry nursing $(14[3.0 \%])$.

\section{Attitude level of graduate health professionals toward CPR}

The minimum and maximum attitude scores of the graduates were 2 and 10 , respectively, with an interquartile range of 2 . The mean attitude score of the students was 7.5 (standard deviation $(\mathrm{SD})=1.67)$. Although the overall attitude score of health science graduates and interns was poor, 263 (57.1\%) of the 461 participants scored $\geq 80 \%$.

The majority of midwifery, anesthesia, and psychiatry nursing graduates and interns were interested in their field of study, except for nursing and health officer students. Most of the graduates were interested in helping patients, except for health officer graduates.

A total of 103 nursing (86.9\%), 128 intern (94.8\%), 60 health officer (75\%), 55 midwifery (71.4\%), 29 anesthesia (90.6\%), and 11 psychiatry nursing (78.6\%) graduates believed that the attitude of health professionals can affect patient outcome following cardiopulmonary arrest.

Only 43 (34.9\%) nurse, 28 intern (20.7\%), 30 health officer (37.5\%), 36 midwifery (46.7\%), 17 anesthesia (53.1\%), and four psychiatry nursing $(28.6 \%)$ graduates said that they were adequately equipped with attitude skills necessary to perform a CPR.
Eighty-two (66.7\%) nursing, 126 intern (93.3\%), 64 health officer(80\%), 52 midwifery (67.5\%), 27 anesthesia (84.4\%), and 9 psychiatry nursing graduates $(64.3 \%)$ said that all health professionals should get BLS training before practicing CPR. A majority of intern (123 [91.1\%]), health officer (64 [80\%]), and 29 anesthesia graduates (90.6\%) said that BLS and ACLS training and certification should be given in undergraduate courses.

Fifty-five (44.7\%) nurse, 101 intern (74.8\%), 30 health officer (37.5\%), 23 midwifery (29.9\%), 20 anesthesia $(62.5 \%)$, and six psychiatry nursing $(42.9 \%)$ graduates were willing to receive training in CPR (Table 1).

\section{Skill level of graduate health professionals with regard to performing CPR}

The minimum and maximum skill scores of graduate health science students and interns with regard to performing CPR were 0 and 8 with an interquartile range of 3 . The mean skill score of students was $2.6(\mathrm{SD}=1.97)$, and the overall skill of students in performing CPR was poor $(<80 \%)$.

A relatively larger number of anesthesia graduates (78.1\%) and interns (74.1\%) attended cardiopulmonary sessions in their curriculum compared to other graduates. Thirty-five (28.5\%) nurse, 43 intern (31.8\%), nine health officer (11.3\%), 19 midwifery (24.7\%), five anesthesia $(15.6 \%)$, and three psychiatry nursing (21.4) graduates attended CPR sessions other than those provided during their curriculum.

Twenty (16.3\%) nursing, 53 intern (39.3\%), seven health officer $(8.7 \%)$, ten midwifery $(12.9 \%)$, eleven anesthesia (34.4\%), and three psychiatric nursing $(21.4 \%)$ graduates explained during data collection that it was less than a one year since they attended the last cardiopulmonary courses.

Nine (7.3\%) nurse, 19 intern (14.1\%), one health officer (1.3\%), seven midwifery ( $9.1 \%)$, and four anesthesia (12.5\%) graduates attended more than five real cardiac arrest cases. None of the students attended more than five real cardiac arrest cases among psychiatry students.

None of the psychiatry students intubated the patients with an endotracheal tube, whereas 23 (18.7\%) nurse, 17 intern (12.6\%), 12 health officer (15\%), and eleven midwifery (14.3\%) students intubated the patients with an endotracheal tube. The majority of anesthesia (30 [93.7\%]) graduates intubated the patients with endotracheal tube.

Only 24 (19.5\%) nursing, five intern (3.7\%), ten health officer (12.5\%), 15 midwifery (19.5\%), three anesthesia $(9.4 \%)$, and two psychiatry nursing $(14.3 \%)$ graduates defibrillated the patients with shockable arrhythmia (Table 2). 

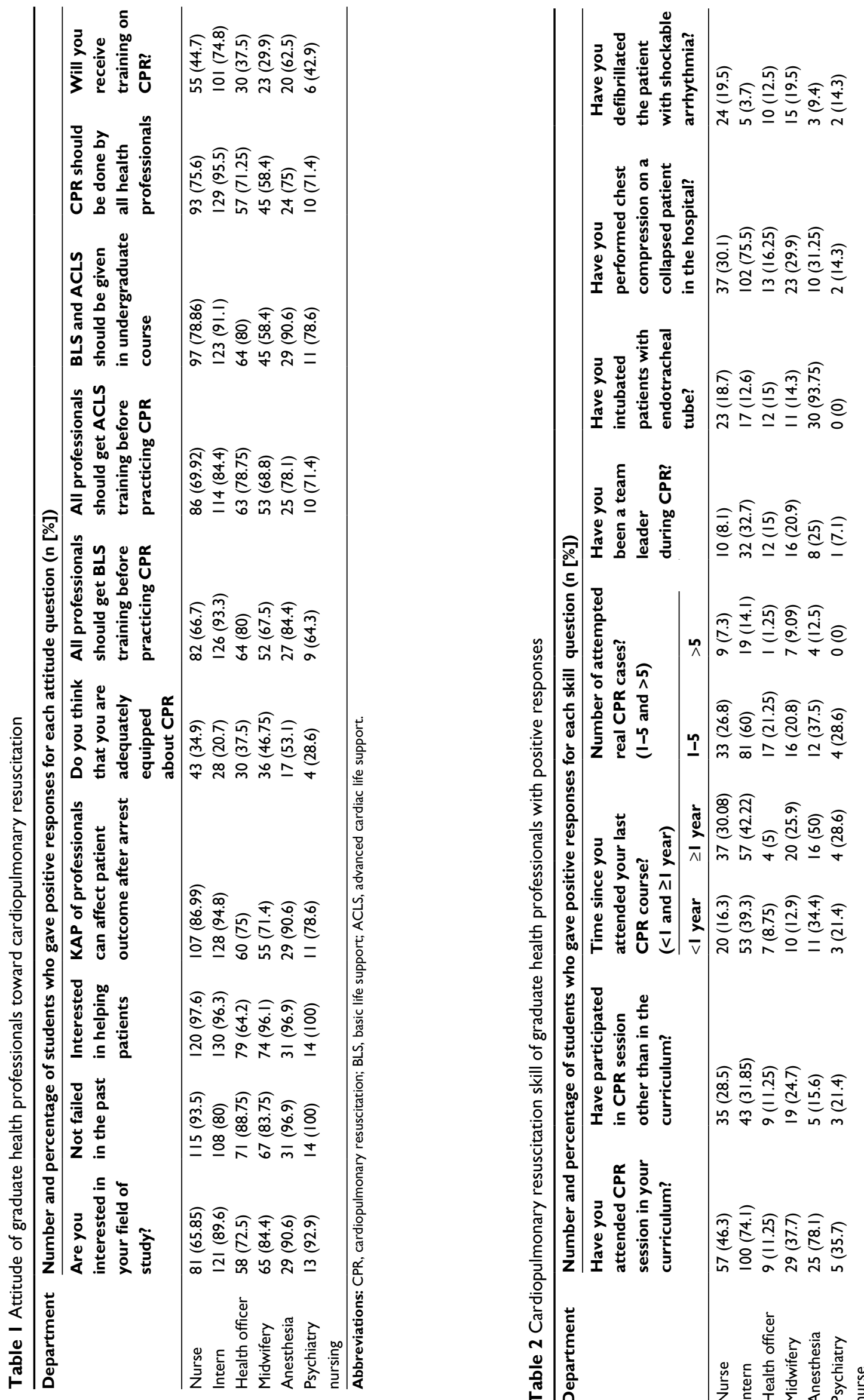

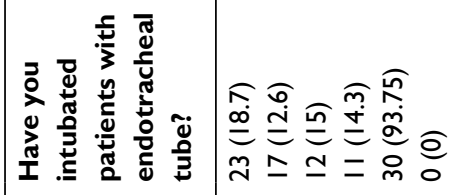

定

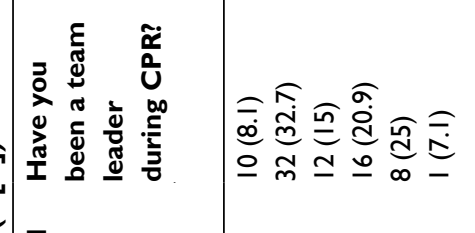

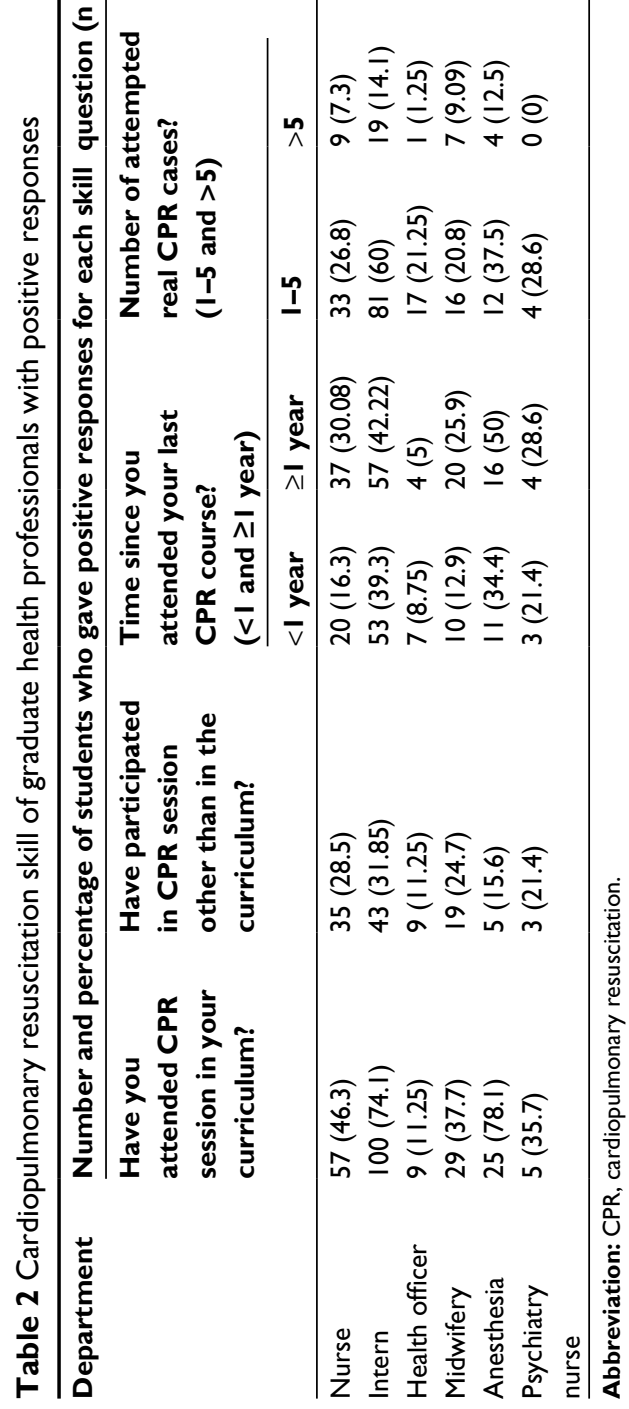




\section{Comparisons of the attitude and skill scores in relation to the different characteristics of the participants}

There was no significant difference in the attitude score in terms of age and sex. The overall difference in the attitude score within different categories was significant with a $P$-value of $<0.001$.

The mean attitude score was significantly different in graduates of different categories (nurses vs interns, $P<0.001$; interns vs nurses, $P<0.001$; interns vs health officers, $P=0.001$; interns vs midwifery, $P<0.001$; midwifery vs anesthesia, $P=0.001)$. The mean attitude score of interns was significantly different from that of graduates of each category (nurse, $P<0.001$; health officer, $P=0.001$; and midwifery, $P<0.001$ ) (Tables 3 and 4).

The skill difference within graduates of different disciplines in relation to the field of study was significant $(P<0.001)$ and was not affected by sex and original residence of graduates.

The mean skill score was significantly different in graduates of different categories (nurses vs interns, $P<0.001$; nurses vs health officers, $P=0.001$; nurses vs anesthesia, $P=0.001$; interns vs health officers, $P<0.001$; interns vs midwifery, $P<0.001$; interns vs anesthesia, $P<0.001$; interns vs psychiatry nursing, $P=0.003$; health officers vs anesthesia, $P<0.001$; health officers vs midwifery, $P=0.029$; midwifery vs anesthesia, $P=0.001$; anesthesia vs psychiatry nursing, $P=0.01$ ).

The mean skill score of anesthesia graduates was significantly different from that of students of each category (nursing, midwifery, $P=0.001$; health officer, $P<0.001$; and psychiatry nursing, $P=0.010$ ). The mean skill score of interns was significantly different from that of students of each category (nursing, health officer, midwifery $[P<0.001]$ and psychiatry nursing $[P=0.003]$ ) (Tables 5 and 6 ).

\section{Discussion}

This study revealed that the overall attitude and skill levels of health science graduates and interns were substandard. The overall mean attitude and skill scores were $7.5(\mathrm{SD}=1.67)$ and 2.6 $(\mathrm{SD}=1.97)$, respectively. Although the overall attitude level was poor, the attitude of more than half $(57.1 \%)$ of the health science graduates and interns was good $(80 \%, n=8)$, which was in line with the 2005 AHA Health professionals' accreditation criteria for CPR.

The mean attitude scores of nurse, intern, health officer, midwifery, anesthesia, and psychiatry nursing graduates were 1.15 ( $\mathrm{SD}=1.67), 8.21$ ( $\mathrm{SD}=1.24), 7.2(\mathrm{SD}=1.49)$, $6.69(\mathrm{SD}=1.83), 8.19(\mathrm{SD}=1.77)$, and $7.29(\mathrm{SD}=2.01)$,
Table 3 Post hoc test of ANOVA (Scheffe's test), multiple comparisons of attitude scores of students from different departments

\begin{tabular}{lll}
\hline Department & Mean difference $(I-J)$ & $P$-value \\
\hline $\begin{array}{l}\text { Nursing } \\
\text { Intern }\end{array}$ & -1.06107 & $<0.001$ \\
Intern & & \\
Health officer & 1.00741 & 0.001 \\
Midwifery & 1.51910 & $<0.001$ \\
Midwifery & & \\
Anesthesia & -1.49919 & 0.001 \\
\hline
\end{tabular}

Note: ${ }^{\text {Reference department. }}$

Abbreviation: ANOVA, analysis of variance.

Table 4 Comparisons of the attitude scores in relation to the different characteristics of the participants, ANOVA test

\begin{tabular}{|c|c|c|c|c|}
\hline Demographics & Number & $\begin{array}{l}\text { Mean } \\
\text { score }\end{array}$ & $\begin{array}{l}\text { Standard } \\
\text { deviation }\end{array}$ & $P$-value \\
\hline \multicolumn{5}{|l|}{ Residence } \\
\hline Rural & 217 & 7.24 & 1.75 & \\
\hline Urban & 244 & 7.67 & 1.58 & $<0.001$ \\
\hline \multicolumn{5}{|l|}{ Department } \\
\hline Nursing & 123 & 1.15 & 1.68 & \\
\hline Intern & 135 & 8.21 & 1.24 & \\
\hline Health officer & 80 & 7.20 & 1.49 & $<0.001$ \\
\hline Midwifery & 77 & 6.69 & 1.83 & \\
\hline Anesthesia & 32 & 8.19 & I.77 & \\
\hline Psychiatry nursing & 14 & 7.29 & 2.02 & \\
\hline
\end{tabular}

Abbreviation: ANOVA, analysis of variance.

Table 5 Post hoc test of ANOVA (Scheffe's test), multiple comparisons of skill scores of students from different departments

\begin{tabular}{lll}
\hline Departments & $\begin{array}{l}\text { Mean difference } \\
(I-J)\end{array}$ & P-value \\
\hline $\begin{array}{lll}\text { Nursing } \\
\quad \text { Intern }\end{array}$ & $-1.4289 \mathrm{I}$ & $<0.001$ \\
$\quad$ Health officer & 1.16646 & 0.001 \\
$\quad$ Anesthesia & -1.53354 & 0.001 \\
Intern $^{\mathrm{a}}$ & & \\
$\quad$ Health officer & 2.59537 & $<0.001$ \\
$\quad$ Midwifery & 1.61453 & $<0.001$ \\
$\quad$ Psychiatry nursing & 2.05608 & 0.003 \\
Health officer & & \\
$\quad$ Anesthesia & -2.70000 & $<0.001$ \\
Midwifery & & \\
Anesthesia & -1.71916 & 0.001 \\
\hline
\end{tabular}

Note: aReference department.

Abbreviation: ANOVA, analysis of variance.

respectively. The attitude of anesthesia graduates and interns was good. This could be due to their frequent involvement in the management of critically ill patients.

The mean skill scores of nurse, intern, health officer, midwifery, anesthesia, and psychiatry nursing graduates were 2.34 $(\mathrm{SD}=1.95), 3.77(\mathrm{SD}=1.58), 1.18(\mathrm{SD}=1.52), 2.16(\mathrm{SD}=1.93)$, $3.88(\mathrm{SD}=1.36)$, and $1.21(\mathrm{SD}=1.77)$, respectively. 
Table 6 Comparisons of the skill scores in relation to the different characteristics of the participants, ANOVA test

\begin{tabular}{lllll}
\hline Demographics & Number & $\begin{array}{l}\text { Mean } \\
\text { score }\end{array}$ & $\begin{array}{l}\text { Standard } \\
\text { deviation }\end{array}$ & P-value \\
\hline $\begin{array}{l}\text { Residence } \\
\quad \text { Rural }\end{array}$ & 217 & 2.29 & 1.89 & 0.001 \\
$\quad \begin{array}{l}\text { Urban } \\
\text { Department }\end{array}$ & 244 & 2.89 & 2.00 & \\
$\quad$ & & & & \\
$\quad$ Nursing & 123 & 2.34 & 1.95 & $<0.001$ \\
$\quad$ Intern & 135 & 3.77 & 1.58 & \\
Health officer & 80 & 1.18 & 1.52 & \\
$\quad$ Midwifery & 77 & 2.16 & 1.93 & \\
$\quad$ Anesthesia & 32 & 3.88 & 1.36 & \\
$\quad \begin{array}{l}\text { Psychiatry } \\
\text { nursing }\end{array}$ & 14 & 1.71 & 1.77 & \\
\hline
\end{tabular}

Abbreviation: ANOVA, analysis of variance.

The attitude of the interns was good, and the mean attitude score was significantly different and higher than that of graduates of each category, except for the students of anesthesia (nurse, $P<0.001$; health officer, $P=0.001$; and midwifery, $P<0.001)$. This finding was in agreement with another study. ${ }^{26}$ This might be due to their frequent exposure to the management of critically ill patients.

The mean skill score of interns was also significantly different and higher than that of graduates of each category, except for the students of anesthesia (nursing, health officer, midwifery $[P<0.001]$ and psychiatry nursing $[P=0.003])$. This could be due to the frequent involvement of the interns in the management of critically ill patients.

The mean attitude score (11.5\%) of the nursing graduates was also poor. This finding was in line with another study. ${ }^{27}$ This could be because of lack of awareness about the advantages of CPR in the management of critically ill patients and limited involvement in the management of critically ill patients during their undergraduate course. In this study, the mean skill score of nursing graduates was also poor. This finding was similar to that reported by another study. ${ }^{29}$ This could be due to their limited exposure to CPR activities.

In our study, the mean attitude (72\%) and skill (14.7\%) scores of health officer graduates were poor. This could be due to the lack of receiving enough training during undergraduate course and inability to attend to adequate number of real CPR cases. This could also be evidenced by the fact that only nine (11.3\%) students attended CPR sessions in their curriculum, 30 (37.5\%) said they were adequately equipped with the attitude and skill to perform CPR, 17 (21.25\%) attended 1-5 real CPR cases, and one (1.3\%) attended more than five real CPR cases during his/her undergraduate course and clinical attachments.

The mean attitude $(66.9 \%)$ and skill $(27 \%)$ scores of graduate midwifery students were poor. This might be due to their limited exposure to CPR cases and insufficient training on BLS and ACLS during their undergraduate course. This could also be evidenced by the fact that only 36 (46.7\%) students said they were adequately equipped with the attitude and skill to perform CPR. Only 29 (37.7\%) and seven (9.1\%) midwifery students said they attended CPR sessions in their curriculum and attended more than five real CPR cases, respectively.

The mean skill (48.5\%) score of anesthesia graduates was poor. Only 25 (78.1\%) attended CPR sessions in their curriculum, 17 (53.1\%) said they were adequately equipped with the attitude and skill to perform CPR, 12 (37.5\%) attended 1-5 real CPR cases, and seven (9.1\%) attended more than five real CPR cases during undergraduate course and clinical practice periods. This finding was in line with a study conducted in Nigeria. ${ }^{32}$ This could be due to a lack of simulation-based training, updating training, and inability get enough number of real CPR cases because of an increase in the number of students in the past 4 years.

The overall mean attitude score $(81.9 \%)$ of anesthesia graduates was good. This might be because of their frequent involvement in the management of critically ill patients and awareness about the advantage of CPR on patient outcome following cardiopulmonary arrest. The mean skill score of anesthesia graduates was also significantly different and higher than that of graduates of each category, except for interns (nursing, midwifery, $P=0.001$; health officer, $P<0.001$; and psychiatry nursing, $P=0.010$ ). This could be due to the frequent involvement of anesthesia students in the management of critically ill patients and in the handling of cardiac arrest cases compared to students from other disciplines.

The mean attitude (72.9\%) and skill (915.1\%) scores of psychiatry nursing graduates were poor. Only five (35.7\%) attended CPR sessions in their curriculum, four (28.6\%) said they were adequately equipped with the attitude and skill to perform CPR, four (28.6\%) attended 1-5 real CPR cases, and none of the students attended more than five real CPR cases during their undergraduate course and clinical attachment. This might be due to their limited chance of handling critically ill patients and lack of updating training and simulation-based training.

\section{Conclusion}

The overall attitude and skill levels of health science graduates and medical interns with regard to performing CPR were insufficient. Although the overall attitude level was substandard, the attitude of more than $50 \%$ of graduate health science students and medical interns toward CPR was sufficient. The mean attitude score of interns was significantly different and higher than those of nursing, health officer, and midwifery 
graduates. Further emphasis should be given on providing training for graduate health professionals.

\section{Acknowledgments}

We thank the study participants and staff for their cooperation during data collection. We deeply regret to inform you that one of the coauthors of this paper Doctor Bernard Bradley Anderson had deceased on January 2, 2014.

\section{Disclosure}

The authors report no conflicts of interest in this work.

\section{References}

1. Govender K, Rangiah C, Ross A, Campbell L. Retention of knowledge of and skills in cardiopulmonary resuscitation among healthcare providers after training. S Afr Fam Pract. 2010;52(5):459-462.

2. Behrend T, Heineman J, Wu L, et al. Retention of cardiopulmonary resuscitation skills in medical students utilizing a high-fidelity patient simulator. Med Student Res J. 2011;1(Spring):1-4.

3. Leong BSH, Chua GSW. Quality of resuscitation in hospitals. Singapore Med J. 2011;52(8):616.

4. Abella BS, Alvarado JP, Myklebust H, et al. Quality of cardiopulmonary resuscitation during in-hospital cardiac arrest. JAMA. 2005;293(3):305-310.

5. Ian J, Vinay N. Cardiac arrest and cardiopulmonary resuscitation outcome reports: update and simplification of the Utstein templates for resuscitation registries: a statement for healthcare professionals from a task force of the international liaison committee on resuscitation (American Heart Association, European Resuscitation Council, Australian Resuscitation Council, New Zealand Resuscitation Council, Heart and Stroke Foundation of Canada, InterAmerican Heart Foundation, Resuscitation Councils of Southern Africa). Circulation. 2004;110(21):3385-3397.

6. Jäntti H. Cardiopulmonary Resuscitation Quality and Education. Publications of the University of Eastern Finland dissertations in health sciences; 2010.

7. Bhanji F, Mancini EM, Sinz E, et al. Part 16: education, implementation, and teams: American Heart Association Guidelines for Cardiopulmonary Resuscitation and Emergency Cardiovascular Care. Circulation AHA. 2010;122(18 Suppl 3):S920-S933.

8. Sutton RM, Niles D, Nysaether J, et al. Quantitative analysis of CPR quality during in-hospital resuscitation of older children and adolescents. Pediatrics. 2009;124(2):494-499.

9. Losert H, Sterz F, Köhler K, et al. Quality of cardiopulmonary resuscitation among highly trained staff in an emergency department setting. Arch Intern Med. 2006;166(21):2375-2380.

10. Peters R, Boyde M. Improving survival after in-hospital cardiac arrest: the Australian experience. Am J Crit Care. 2007;16(3):240-246.

11. El-Menyar AA. The resuscitation outcome. Chest. 2005;128:2835-2846.

12. Topjian AA, Berg RA, Nadkarni VM. Pediatric cardiopulmonary resuscitation: advances in science, techniques, and outcomes. Pediatrics. 2008;122(5): 1086-1098.

13. Moretti MA, Cesar LA, Nusbacher A, Kern KB, Timerman S, Ramires JA. Advanced cardiac life support training improves long-term survival from in-hospital cardiac arrest. Resuscitation. 2007;72(3):458-465.

14. Falcão LF, Ferez D, Amaral JL. Update on cardiopulmonary resuscitation guidelines of interest to anesthesiologists. Rev Bras Anestesiol. 2011;61(5):624-640.
15. Chew F Z A W M N KS, Mohd Hashairi F, Ida Zarina Z, Shaik Farid AW, Abu Yazid MN, Nik Hisamuddin NA. A survey on the knowledge, attitude and confidence level of adult cardiopulmonary resuscitation among junior doctors in hospital Universiti Sains Malaysia and Hospital Raja Perempuan Zainab II, Kota Bharu, Kelantan, Malaysia. Med J Malaysia. 2011;66(1):56-59.

16. Høyer CB, Christense EF, Eika B. Junior physician skill and behaviour in resuscitation: a simulation study. Resuscitation. 2009;80(2):244-248.

17. Sheng CK, Zakaria MI, Rahman NH, Jaalam K, Adnan WA. Cardiopulmonary resuscitation: the short comings in Malaysia. Malays J Med Sci. 2008;15(1):49-51.

18. AL-Kadary S, Al-Jeheili A, Ghayath T, Al-Haid N. Perceived competence in cardiopulmonary resuscitation knowledge and practice among qualified nurses in Kuwait. Bull Allex Fac Med. 2007;43:2.

19. Madden C. Undergraduate nursing students' acquisition and retention of CPR knowledge and skills. Nurse Educ Today. 2006;26(3):218-227.

20. Verplancke T, De Paepe P, Calle PA, et al. Determinants of the quality of basic life support by hospital nurses. Resuscitation. 2008;77(1):75-80.

21. Abdollahi AA, Yazdi Kh, Hosseini SA, Khoddam H. Effect of station training method on students' cardiopulmonary resuscitation activity. IJCCN. 2010;3(3):105-108.

22. Ravari H, Abrishami M, Ghezel-Sofla M, Vahedian-Shahroodi M, Abrishami M. Knowledge of Iranian medical interns regarding cardiopulmonary resuscitation. Trauma Mon. 2012;17(1):242-244.

23. Li Q, Ma EL, Liu J, Fang LQ, Xia T. Pre-training evaluation and feedback improve medical students' skills in basic life support. Med Teach. 2011;33(10):e549-e555.

24. Eikeland Husebø SI, Bjørshol CA, Rystedt H, Friberg F, Søreide E. A comparative study of defibrillation and cardiopulmonary resuscitation performance during simulated cardiac arrest in nursing student teams. Scand J Trauma Resusc Emerg Med. 2012;20:23.

25. Zaheer H, Haque Z. Awareness about BLS (CPR) among medical students: status and requirements. J Pak Med Assoc. 2009;59(1):57-59.

26. Price CS, Bell SF, Janes SE, Ardagh M. Cardio-pulmonary resuscitation training, knowledge and attitudes of newly-qualified doctors in New Zealand, 2003. Resuscitation. 2006;68(2):295-299.

27. Niemi-Murola L, Mäkinen M, Castren M; ECCE Study Group. Medical and nursing students' attitudes toward cardiopulmonary resuscitation and current practice guidelines. Resuscitation. 2007;72(2):257-263.

28. Chandrasekaran S, Kumar S, Bhat SA, Saravanakumar, Shabbir PM, Chandrasekaran V. Awareness of basic life support among medical, dental, nursing students and doctors. Indian JAnaesth. 2010;54(2):121-126.

29. Nyman J, Sihyonen M. Cardiopulmonary resuscitation skills in nurses and nursing students. Resuscitation. 2000;47(2):179-184.

30. Al-Turki YA, Al-fraih YS, Jalaly JB, et al. Knowledge and attitudes towards cardiopulmonary resuscitation among University students in Riyadh, Saudi Arabia. Saudi Med J. 2008;29 (9):1306-1309.

31. Hopstock LA. Cardiopulmonary resuscitation; use, training and selfconfidence in skills. A self-report study among hospital personnel. Scand J Trauma Resusc Emerg Med. 2008;16:18.

32. Desalu I, Olanrewaju O, Olutola O. Training and confidence level of junior anaesthetists in CPR-experience in a developing country. Indian J Anaesth. 2008;52(3):297-300.

33. Gebremedhn EG, Gebregergs GB, Anderson BB. The knowledge level of final year undergraduate health science students and medical interns about cardiopulmonary resuscitation at a University Teaching Hospital of Northwest Ethiopia. World J Emerg Med. 2014;5(1):29-34.

34. Resuscitation Council (UK). Guidelines 2010. Available from https:// www.resus.org.uk/archive/guidelines-2010/. Accessed December 1, 2016.

35. American Heart Association 2005. Guidelines for cardiopulmonary resuscitation and emergency cardiovascular care. Circulation. 2005; 112(24):1-203. 
Advances in Medical Education and Practice

Dovepress

\section{Publish your work in this journal}

Advances in Medical Education and Practice is an international, peerreviewed, open access journal that aims to present and publish research on Medical Education covering medical, dental, nursing and allied health care professional education. The journal covers undergraduate education, postgraduate training and continuing medical education

including emerging trends and innovative models linking education, research, and health care services. The manuscript management system is completely online and includes a very quick and fair peer-review system. Visit http://www.dovepress.com/testimonials.php to read real quotes from published authors.

Submit your manuscript here: http://www.dovepress.com/advances-in-medical-education-and-practice-journal 